\title{
Demand Shifting as a Profitable Strategy for Solar Plant Operators
}

\author{
Ashling Leilaeioun ${ }^{1}$, Russell K Jones ${ }^{2}$, Senior Member, Ronald A. Sinton ${ }^{3}$, and Sarah Kurtz ${ }^{1}$ \\ 1. University of California Merced, Merced, CA \\ 2. Jones Solar Engineering, Manhattan Beach, CA; \\ 3. Sinton Instruments, Boulder, CO
}

\begin{abstract}
As solar electricity generation increases, the daytime net load (total load less solar generation) decreases, reducing prices in the middle of the day. These low prices reduce motivation to invest in more solar electricity. In this study, the correlation between net load and price is quantified on a seasonal average basis, and used to predict resulting hourly price changes if demand can be shifted from evening peak hours to mid-day when solar generation is greatest. The results suggest such a strategy will be of economic benefit to solar generators by increasing the price at mid-day for all electricity delivered, while reducing the price and thus total expenditures for energy during evening peak hours, with a net overall savings for energy consumers. These financial benefits motivate solar plant owners and developers to promote load-shifting, both to increase the revenue from current solar plants and to create demand for more solar plants.
\end{abstract}

Keywords-demand management, electricity markets, duck curve

\section{INTRODUCTION AND MOTIVATION}

The portion of energy in California generated by solar energy increased by 52x from 2010 to 2019, and in 2020 solar energy accounted for $22.7 \%$ of all generation[1]. Each morning, as the sun rises, thermal generation sources ramp down and a large fraction of the total load during the mid-day is served by solar generators. Then in the afternoon, as the sun sets and solar generation fades, thermal generation sources (primarily gas) must ramp up to satisfy the total load through the evening peak demand and overnight. The California independent system operator (CAISO) gave the resulting net load daily cycle the moniker "the duck curve"[2], which is illustrated in Fig. 1.

CAISO provides the central management of electricity operations in California, including operation of the electricity trading market. At the system (wholesale) level, most of the electricity purchased from generators and delivered to consumers is bought and sold in the day-ahead market, in which bids to purchase electricity and bids to sell electricity are organized with a "bid stack" for each: bids to purchase electricity are stacked from highest price to lowest, whereas bids to sell electricity are stacked from lowest to highest, and the price at which these two stacks meet is the "clearing price", which changes hour-to-hour throughout the day[3]. In each operating hour, all of the generators delivering energy in that hour are remunerated at the clearing price. Because solar energy plants have virtually no marginal cost of generating power, their energy is generally offered at the lowest price, and the availability of large amounts of solar energy suppresses mid-day

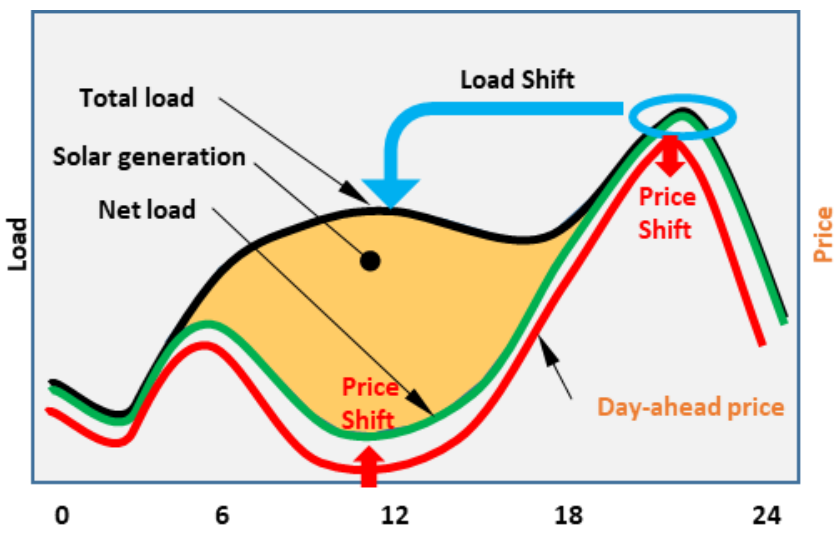

Fig. 1. The "duck curve" and notional objective of the study.

prices, whereas prices rise as the amount of thermal generation rises to meet afternoon and early evening demand. Indeed, it is observed that the day-ahead price (red line) is highly correlated with the net load (green line), as depicted in Fig. 1.

California has established (through the SB100 state law)[4] ambitious targets for decarbonizing electricity generation in the state, aiming for $100 \%$ carbon-free electricity by 2045 . Recently, even more ambitious timelines have been introduced at the federal level[5]. It is expected that solar energy will play a leading role in achieving the goal of $100 \%$ carbon-free electricity; however, solar energy has the obvious drawback of being available only during daylight hours. For solar energy to play a larger role, energy storage must be employed to serve nighttime loads - or nighttime demand can be shifted into daylight hours.

Load shifting has an important distinction from traditional demand response services, which have been primarily in the form of load shedding of large industrial loads under command of the utility, remunerated by capacity payments and/or very high peak pricing for the load reduction, treated equivalently to peak generation by the market. Load shifting by contrast is not a reduction in demand, but rather a shift in the timing of demand, whether through use of storage in some form or by taking advantage of inherent flexibility in the timing of loads. A wellknown example of load shifting is through the use of chilled water or ice storage to meet building cooling loads, which until now has generally been used to shift load into nighttime because electricity tariffs until now are lowest at night, but may in the future shift load to mid-day as solar energy makes mid-day power the lowest cost. More widespread adoption of chilled water storage (including in the residential sector) could enable 
much more load shifting in the carbon-free grid, and there are many other potential load uses amenable to shifting in the industrial, commercial, and residential sectors. Other prominent examples include space heating, industrial process heat, water pumping, refrigeration, and electric vehicle charging. Finally, of course, load can be shifted for any type of load by charging and discharging batteries.

Load shifting is, however, not free. Some opportunities, such as EV charging, may be nearly free and involve changing consumer behavior; others require installation or modification of consumer premise equipment at varying cost points. A recent comprehensive study by Gerke et.al.[6] has explored the potential for many load-shifting use cases and quantified their estimated cost of implementation using the cost of batteries as a benchmark. The study showed that non-battery load shifting of $\sim 6 \mathrm{GWh}$ per day can be accomplished at lower cost than batteries in California, mainly with industrial process loads, agricultural pumping, and commercial HVAC.

This paper is focused on price rather than cost, and explores how load shifting may impact the day-ahead market prices as suggested in Fig. 1. We quantify how shifting load from the peak hour to mid-day is expected to impact the price at both times based on historical data. Because all generators supplying energy during a given trading hour are compensated at the clearing price, the price shift expected in response to a load shift will be leveraged to amplify the benefits and costs to all generators selected in the bid stack at market clearing. As a final step, the changes in overall market expenditures and revenue for the mid-day solar generators are compared to the estimated costs from the Gerke study.

\section{Methodology}

The data used in this study were accessed through publicly available historical datasets published by CAISO for load and generation sources[7] and, separately, for day-ahead price[8].

As a preliminary step, Fig. 2 shows daily peak prices in the day-ahead market over several years and reveals that there is considerable volatility in the peak prices (indeed the plot for 2018 does not show the true peak, which reached $\$ 976.39$ on 25 July[8]). Such volatility can result from a variety of influences, such as outages in generation plants or transmission lines, but generally simply follows gas prices. The price spikes in JulyAugust and February 2019 were attributed by CAISO to volatility in gas prices[9].

To establish the functional relationship between net load and day-ahead prices during the majority of days, we seasonally averaged both net load and price at each hour for the spring, summer, fall, and winter seasons. The resulting curves in Fig. 3 show the high degree of correlation that exists. In Fig. 4 the data of Fig. 3 have been re-cast as price versus net load, from which the price sensitivity to changes in net load is taken as the slope of a linear fit found by least squares regression.

Armed with these price sensitivities, the anticipated price impact of load shifting was calculated for various load shifting scenarios. In Fig. 5 the price changes are calculated for the case of a shift of $6 \mathrm{GWh}$ total over a period of 3 hours $(2 \mathrm{GWh}$ per hour). On the top row of the figure, the load, solar generation delivered, and curtailment are shown before and after load

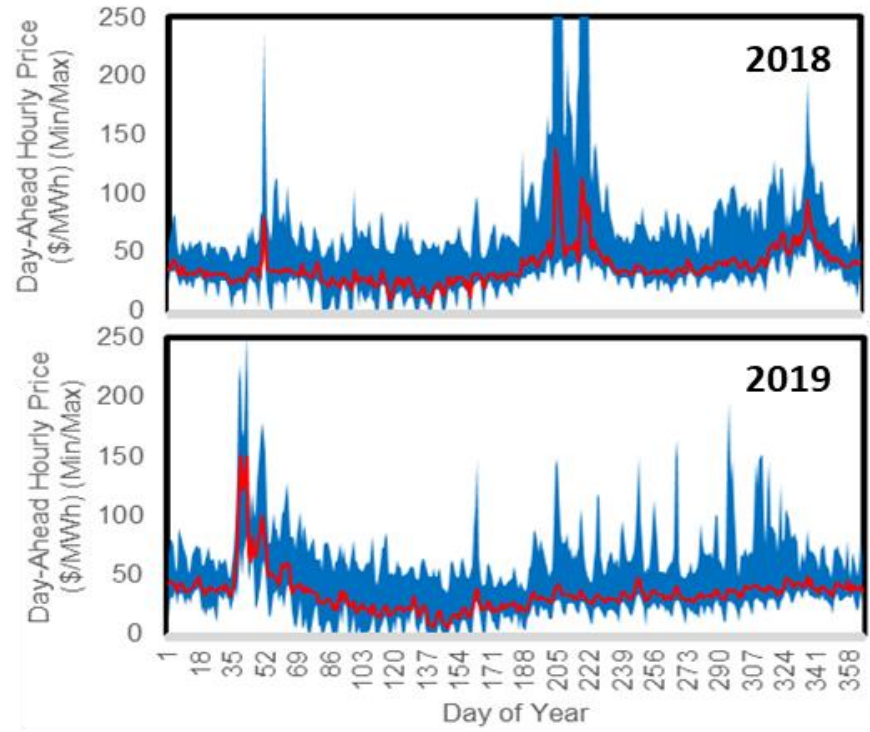

Fig. 2. Range of day-ahead electricity price values. The red curve is the median daily price.
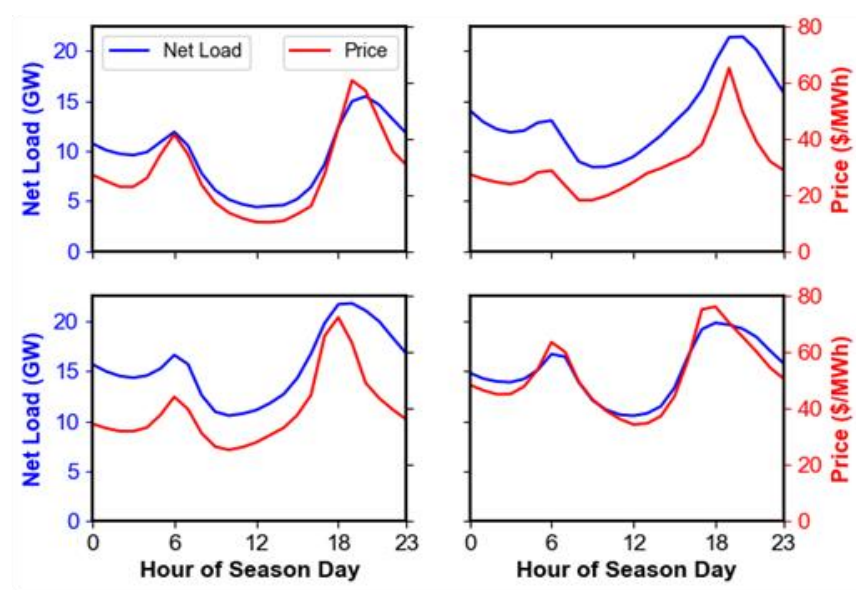

Fig. 3. Correlation of the net load and day-ahead price. These curves are seasonally averaged over spring (days 59-150), summer (days 151-242), fall (days 243-333), and winter (days 334-365 and $1-58)$, capping prices greater than $\$ 150 / \mathrm{MWh}$.
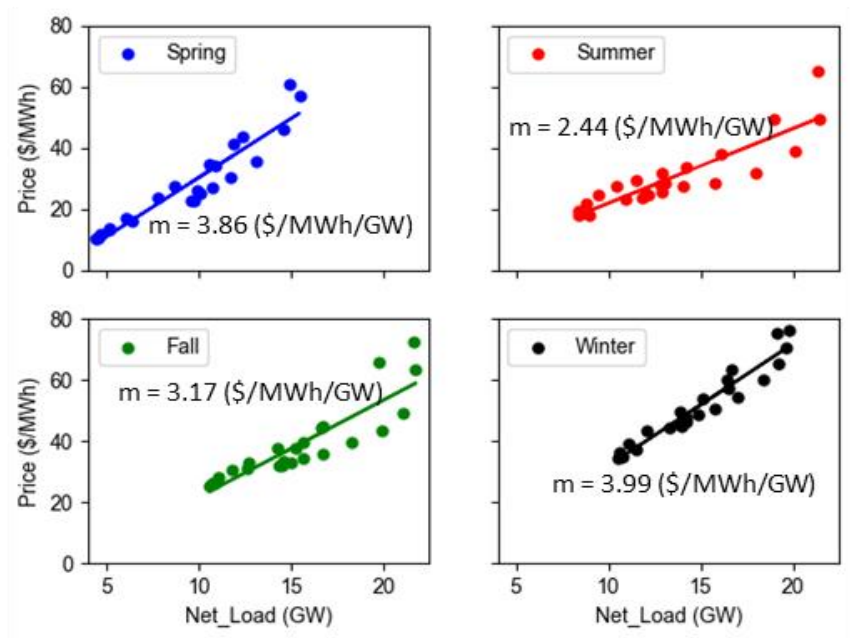

Fig. 4. Price sensitivity to net load, based on seasonal averages of net load and day-ahead price. 

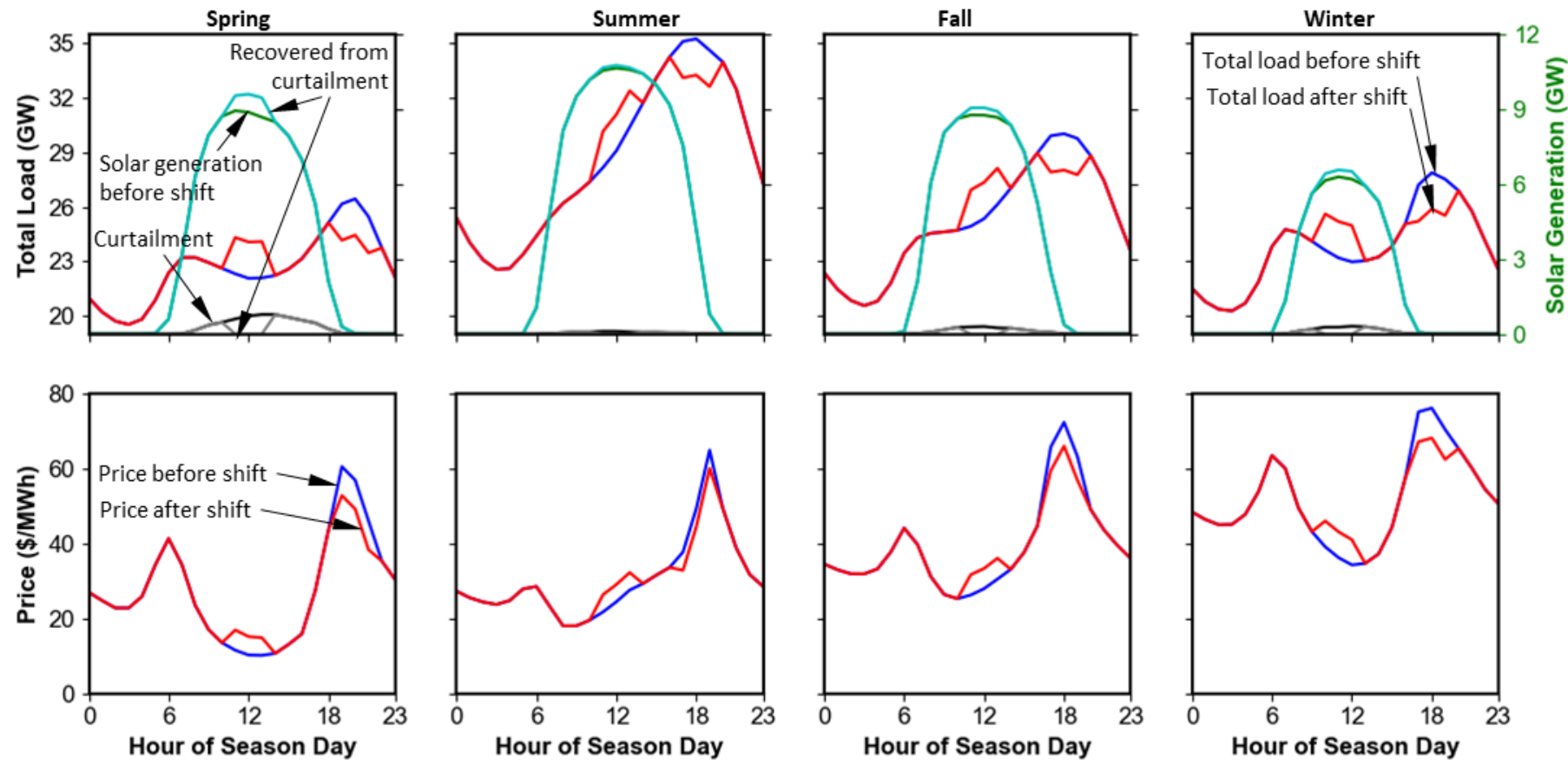

Fig. 5. Total load, solar generation, and solar curtailment (top) and price (bottom) before and after shift of $6 \mathrm{GWh}$ load over 3 hours ( $2 \mathrm{GWh}$ in each hour). The solar generation is modified by delivering energy that would otherwise be curtailed. The curtailed energy is used first in each hour, and any remaining shifted load increases net load.

shifting, and on the bottom the resulting modified price curve is shown before and after shifting. Note the range of the y-axis for total load; the variation between minimum and maximum is about $25-35 \%$ of the peak, depending on season. The load shifting strategy employed is to move energy from the highest load hour to the highest solar generation hour, then from the second highest load hour to the second-highest solar generation hour, and so on, for as many hours as specified (in this case 3 hours).

Although there is almost no curtailment in the summer, some curtailment is present in the other seasons (particularly for spring). When curtailment is present in the historical data (again seasonally averaged in this analysis), the shifted load is first satisfied by reducing the curtailment, and if the shifted load exceeds the amount that can be supplied from the curtailed energy, it increases the net load to be met by thermal generators.

\section{RESULTS AND DISCUSSION}

A complete numerical example is provided in Table I, showing how the load shift and resulting price change impacts the solar and thermal generators and the system as a whole. In this scenario, $2 \mathrm{GWh}$ was shifted in a single hour. Again, the strategy employed is to shift from the highest load hour to the highest solar generation hour.

Following the same logic, and returning to the scenario of Fig. 5, Fig. 6 shows the revenue gains and losses for each generator class ("other" includes biomass and geothermal). It is evident that while solar generators gain revenue, all other generator classes lose revenue.
Fig. 6 shows that the benefit of this load shifting to solar generators is substantial ( $\sim 7 \%$ revenue boost), whereas thermal generators suffer the biggest losses because it is they who have the greatest share of the generation mix at the evening peak. The capacity factor of the solar plants is increased slightly because previously curtailed energy is delivered to load after the shift; the capacity factor of thermal generators is somewhat reduced by the same amount (some thermal generation is substituted with otherwise curtailed energy). The net result is to increase the value of solar plants while decreasing the viability of thermal generation plants.

The strategy that has been employed subtracts load from the hours with the highest price and adds to the load when the greatest solar generation occurs. This strategy is non-optimal for the system, because in the summer, the lowest daily prices occur in the early morning when there is not much solar generation, and a greater system benefit could be gained by adding to the load at that hour than by adding to the mid-day load. The strategy is also non-optimal for the solar generators, because in every season there is some solar generation remaining at the peak load hour (indeed, in the example shown in Table I the remaining solar generation exceeds the amount shifted). The strategy is thus "cannibalizing" the revenue for the solar generators at the highest price hour. Even so, the solar generators still realize a net gain in the summer example due to the higher amount of energy being delivered at mid-day and the leveraging effect of the higher mid-day clearing price on that large amount of generation. The solar generators would benefit in this case by a strategy that shifts load from an hour later when there is no resulting solar revenue loss.

The analysis assumes that all curtailed energy is available to satisfy shifted load. Curtailment is primarily due to 


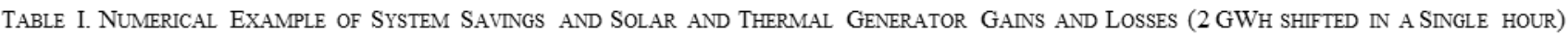

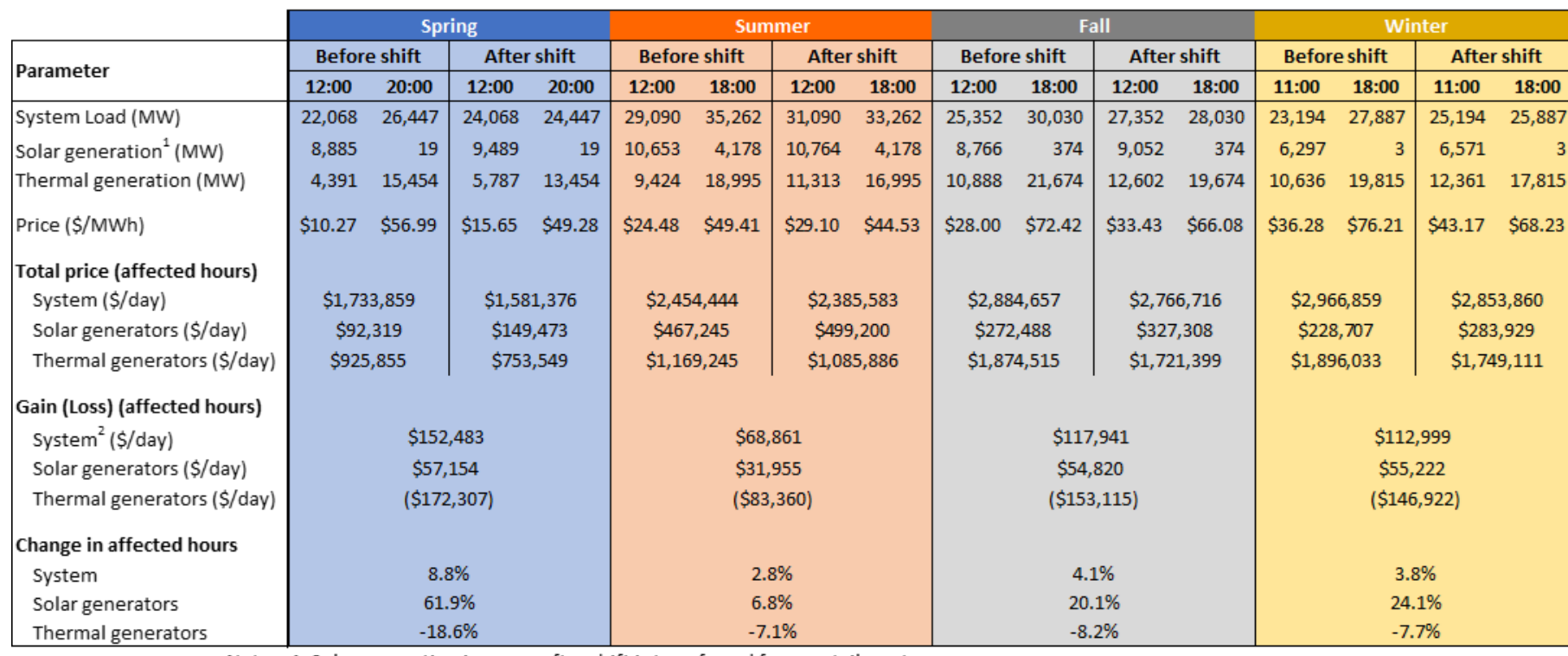

Notes: 1 . Solar generation increase after shift is transferred from curtailment.

2. System gain is net reduction in total expenditure to procure electricity.
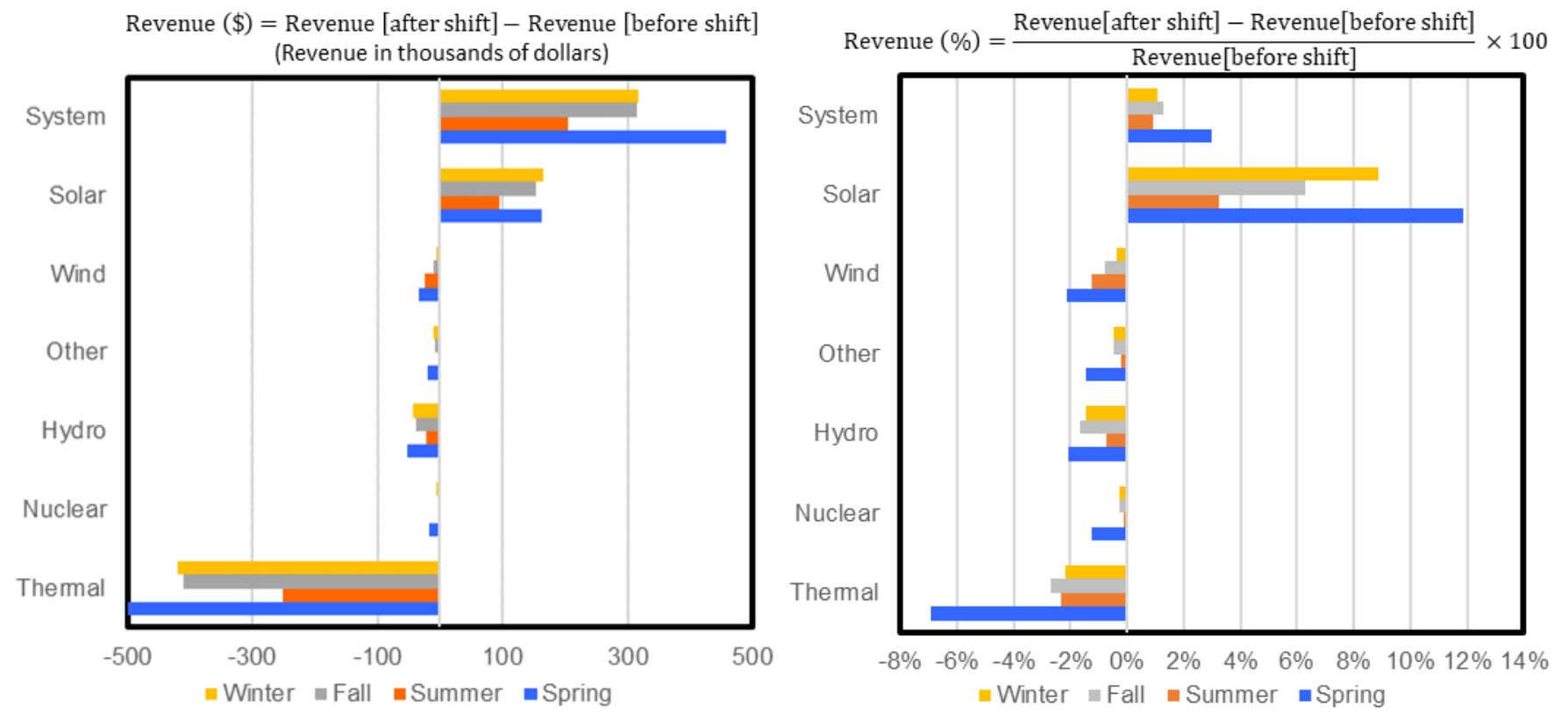

Fig. 6. Net revenue gains and losses for the participating generation sources. Calculated for the scenario of $6 \mathrm{GWh}$ total load shifted over 3 hours (2GHw shifted in each hour)..

congestion[10], so the load shifting should be accomplished near the solar plant to facilitate delivery of the otherwise curtailed electricity to the shifted load.

This analysis has been premised on the assumption that the price is responsive to load shifts in proportion to the observed relationship between day-ahead price and net load. This assumption needs further exploration and validation.

Returning now to the study of cost potential for load shifting presented by Gerke et.al. in Ref. 6, it is worth considering how these forecasted revenue shifts compare with the forecasted cost to implement various measures. Fig. 7 shows a comparison. The gains to solar generators alone are insufficient to offset the implementation costs, but the system savings are of greater magnitude and can profitably cover up to $2 \mathrm{GWh}$ /day of load shifting by 2025 . With declining costs forecasted by the Gerke study, this figure grows to perhaps $2.5 \mathrm{GWh}$ /day by 2030 . The gains can offset the implementation cost of any type of load shift, whether battery or other approaches. A caveat, however, is that the gains have been calculated based on 2019 data and may be modified by changes in the energy mix, primarily as a result of solar capacity growth. A further caveat is that we have combined the price effects over the year, and they are greatest in the spring (when heating and cooling loads are low, and solar generation is comparatively high) but the non-battery load shift 


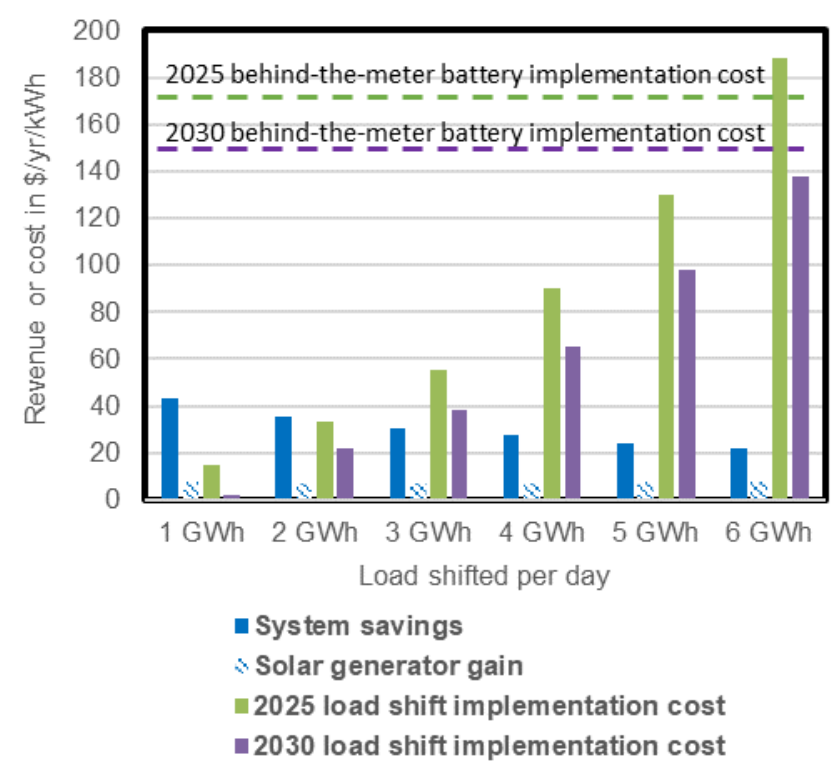

F1g. 7. A comparison of the forecasted tinancial benetits of load shitting with their implementation costs. The gain in revenue for solar generators, shown for reference, is a portion of the systems savings. The implementation costs (bars) are for non-battery load shift technologies, and the lines are for battery implementation costs, from Ref. 6 .

opportunities are generally seasonal in nature (such as HVAC loads) and are lowest in the spring and fall.

A plausible strategy to motivate load shifting is to adjust time-of-use (TOU) rates that reduce a consumer's bill when load-shifting is implemented. Solar advocates have typically lobbied against TOU rates because these tend to reduce the apparent value of solar electricity. Ironically, solar advocates may consider that, while the TOU rates appear to reduce the value of solar electricity, the load shifting that they motivate can increase revenue for solar plant owners and empower solar to grow further. Thus, the time has come for solar advocates to reconsider their strategic approach to policy changes and support policies that incentivize load shifting.

\section{CONCLUSION}

For PV penetration to grow much beyond about $20 \%$, some form of load shifting will be essential, via batteries or other avenues. The effect of price response to shifting loads may be rightly viewed as a sweetener to encourage the implementation of load shifting, by improving the return on investment from the system point of view. The benefits to the demand-shifting consumers (by getting a lower price for their consumed energy) and to all consumers (by getting a lower price at the highest price hours) are aligned to those of the solar generators. Thus, it may behoove solar operators and consumer stakeholders to work together advocating policies and incentives to facilitate load shifting technology enablers and pricing schemes. Such policy advocacy should also be supported by public interest stakeholders more generally since the strategy leads to overall lower electricity cost and reduced emissions from fossil fuel generators.

\section{ACKNOWLEDGEMENTS}

This document was prepared in connection with work sponsored by the California Energy Commission. It does not necessarily represent the views of the Energy Commission, its employees, or the State of California. The Energy Commission, the State of California, its employees, contractors, and subcontractors make no warranty, express or implied, and assume no legal liability for the information in this document; nor does any party represent that the use of this information will not infringe upon privately owned rights. This report has not been approved or disapproved by the Energy Commission nor has the Energy Commission passed upon the accuracy of the information in this report.

\section{REFERENCES}

[1] David Feldman and Robert Margolis, H2 2020 Solar Industry Update, National Renewable Energy Laboratory Report NREL/PR-7A40-79758, 6 April 2021, https://www.nrel.gov/docs/fy21osti/79758.pdf.

[2] Paul Denholm, Matthew O'Connell, Gregory Brinkman, and Jennie Jorgenson, "Overgeneration from Solar Energy in California: A Field Guide to the Duck Chart", National Renewable Energy Laboratory Technical Report NREL/TP-6A20-65023, November 2015.

[3] Cynthia Hinman, "Day-Ahead Market Overview", California ISO presentation 2 December 2019, retrieved from CAISO website. http://www.caiso.com/Pages/documentsbygroup.aspx?GroupID=9BA43 A8C-F150-4E84-9ACB-FE5CCE0BAD2B, retrieved 10 May 2021.

[4] California Senate Bill 100, https://focus.senate.ca.gov/sb100, retrieved 10 May 2021.

[5] United States White House Fact Sheet, "President Biden Sets 2030 Greenhouse Gas Pollution Reduction Target Aimed at Creating GoodPaying Union Jobs and Securing U.S. Leadership on Clean Energy Technologies", 22 April 2021.

[6] Brian F. Gerke, Giulia Gallo, Sarah J. Smith, Jingjing Liu, Peter Alstone, Shuba Raghavan, Peter Schwartz, Mary Ann Piette, Rongxin Yin, and Sofia Stensson, The California Demand Response Potential Study, Phase 3:Final Report on the Shift Resource through 2030, July 14, 2020, DOI 10.20357/B7MS40.

[7] California ISO, "Managing Oversupply", Production and Curtailment Data, http://www.caiso.com/informed/Pages/ManagingOversupply.aspx

[8] LCG Consulting "Energyonline" website, CAISO Day-Ahead Pricing, http://www.energyonline.com/Data/GenericData.aspx?DataId=22\&CAI SO_Day-Ahead_Price

[9] "Price Performance in the CAISO's Energy Markets", CAISO Market Analysis and Forecasting Report, June 18, 2019, retrieved from http://www.caiso.com/Documents/ReportPricePerformanceAnalysis.pdf

[10] Schermeyer, Hans, Claudio Vergara, and Wolf Fichtner. "Renewable energy curtailment: A case study on today's and tomorrow's congestion management." Energy Policy 112 (2018): 427-436. 